In Diego E. Machuca (ed.), Pyrrhonism in Ancient, Modern, and Contemporary

Philosophy, Dordrecht: Springer, 203-215.

\title{
SKEPTICISM AND DISAGREEMENT
}

Markus Lammenranta

University of Helsinki

The most significant feature of ancient Pyrrhonian skepticism was its reliance on disagreement. This aspect of skepticism has been widely neglected in contemporary discussion on skepticism, and indeed had hardly been mentioned until it became a hot topic quite recently. Even now, the skeptical power of disagreement is not fully appreciated. At most, it is thought to warrant suspension of belief in very restricted circumstances, ${ }^{1}$ which is in sharp contrast to ancient Pyrrhonian skepticism, which appeals to disagreement in inducing the global suspension of belief.

My aim is to reconstruct the skeptical reasoning that is based on disagreement. I will endeavor to show that this rational reconstruction provides a genuine skeptical paradox that we should take seriously in constructing our theories of knowledge and justification. It also accounts for the close connection that skepticism has traditionally been assumed to have with relativism.

As Sextus Empiricus explained, the skeptical strategy consists of three stages: The skeptic first points out or argues that there are disagreements on some question, then tries to show that these disagreements cannot be resolved, and finally concludes that we should suspend belief about the matter. This strategy is apparent both in the ten modes of Aenesidemus and in the five modes of Agrippa ( $P H$ 1.35-177).

Suppose there is a question to which there are just two possible answers, $p$ and $\sim p$, and we disagree: I believe that $p$, and you believe that $\sim p$. The skeptical argument then takes the following form:

1. I believe that $p$.

2. You believe that $\sim p$.

3. At most one of us is right. 
4. The disagreement between us is rationally irresolvable.

5. I should suspend belief about $p .^{2}$

The skeptic propounds this as an ad hominem argument. ${ }^{3}$ It is directed against one of my beliefs, and the idea is to get me to accept each premise and step of it and to force me to accept the conclusion. Furthermore, the skeptic claims to be able to construct a similar argument against any of my beliefs about the nature of reality.

When Sextus described the skeptical strategy — especially in the ten modes — he put a lot of effort into showing that there were disagreements, that there were other human and even nonhuman subjects to which things appeared differently, or that at least there could be such subjects. One could raise some doubts about whether all the cases in the literature are cases of genuine disagreement in which one party affirms and the other one denies one and the same proposition, or in which they attribute incompatible properties to the same object. I do grant, however, that there are enough such cases to which the skeptic can appeal. Indeed, it is enough if there is only one such case for each of my beliefs.

I also grant that lemma three follows from premises one and two, although there may be relativists who deny this because they think that we can both be right: $p$ is true for me, and $\sim p$ is true for you. According to such alethic or Protagorean relativism, we can both rationally retain our beliefs. Relativism thus avoids skepticism in denying that there is genuine disagreement between the disputing parties. ${ }^{4}$ Although this is one possible response to the skeptical argument, I will leave discussion about relativism for another occasion ${ }^{5}$ here, merely assume that it is not an intuitively attractive position. It may not even be coherent. If anyone is attracted to it after considering all possible responses to the Pyrrhonian argument, I take this to confirm my point that the argument forms a genuine paradox.

The epistemologically interesting part of the strategy is premise four and the question whether the conclusion follows from it. Let us focus on this part and reformulate the skeptical argument as follows:

1. There is a serious rationally irresolvable disagreement about $p$. 
2. If there is a serious rationally irresolvable disagreement about $p$, then I should suspend belief about $p$.

3. So I should suspend belief about $p$.

My claim is that this argument forms a skeptical paradox. The skeptic manages to make the premises very plausible, and the conclusion follows deductively from them. However, because $p$ may be any proposition about the nature of reality, the conclusion can hardly be accepted. Therefore, both of the premises and the denial of the conclusion are all plausible, but they cannot all be true because they form an inconsistent set.

In order to establish the plausibility of the premises we must clarify the argument at three points. First, we need to be clear about what the skeptic means by an irresolvable disagreement. Sextus also refers to equipollent opposition, and sometimes explains it in psychological terms:

By equipollence we mean equality with regard to being convincing or unconvincing. Suspension of judgement is a standstill of the intellect, owing to which we neither reject nor posit anything. Tranquillity is freedom from disturbance or calmness of soul. (PH 1.10)

In his paper "Skepticism without Theory" Michael Williams (1988, 554-555) based his interpretation of the Pyrrhonian problem on passages like this, arguing that Pyrrhonian skepticism is an ability to oppose any thesis or argument with a countervailing thesis or argument of equal force. He emphasized that no epistemological commitments are buried in this notion of equal force, which is to be understood as equal convincingness or plausibility. Equipollence is thus to be understood purely psychologically.

The problem is that this understanding of Pyrrhonism hardly provides a serious skeptical problem. There are not many cases in which we find contradictory propositions equally plausible and are therefore forced to suspend belief. Thus it would be too easy for the dogmatist to reject the first premise. If he or she just sticks to this belief there is nothing that the skeptic can do. 
Furthermore, this interpretation makes it hard to understand why Sextus emphasized dispute or disagreement. In a simple disagreement one party finds one proposition plausible and the other finds its negation plausible. It is not the case that both find the proposition and its negation equally plausible. If it were there would be no dispute.

Indeed, in many passages Sextus made it clear that the problem was not psychological:

For we shall not be able ourselves to decide between our own appearances and those of other animals, being ourselves a part of the dispute and for that reason more in need of someone to decide than ourselves able to judge. (PH 1.59)

When the self-satisfied Dogmatists say that they themselves should be preferred to other humans in judging things, we know that their claim is absurd. For they are themselves a part of the dispute, and if it is by preferring themselves that they judge what is apparent, then by entrusting the judging to themselves they are taking for granted the matter being investigated before beginning the judging. ( $P H$ 1.90)

Here he was not claiming that we could not resolve a disagreement because the contradictory answers to some question were equally plausible, but because as participants in the dispute we should not prefer our own appearances or judgments to those of the other participants. That would beg the question. We would need some impartial grounds or judge in order to resolve the dispute. It is clear that Sextus was not referring to the psychological inability to judge. He was quite ready to acknowledge that dogmatists did judge the appearances, and that they preferred their own to those of others who disagreed with them. The point is that they could not do this without violating the rules of dialectic.

It seems clear that Sextus took our inability to resolve disagreements to be a dialectical failure. What, then, is needed for the rational resolution of a disagreement in this dialectical sense? Suppose I believe that $\mathrm{p}$, and you believe that $\sim \mathrm{p}$. I could resolve this disagreement if I had an argument for my belief that you considered 
sound. You would accept its premises and take it to be (either deductively or inductively) valid, and this would be enough to rationally convince you. I could also resolve the disagreement more indirectly by putting forward an ad hominem argument starting from premises that you accepted and arriving at the conclusion that your belief was false. In either case you would be rationally required to give up your belief. And of course, the disagreement would also be resolved if you could do either of these things to me. If neither of us succeeded in this our disagreement would be rationally irresolvable.

Perhaps, there are irresolvable disagreements of this sort that nobody takes seriously. They may be cases in which one party is irrational or in some other way deficient and cannot therefore be rationally convinced, which is why I add the qualification "serious" to the skeptical argument. In serious cases of disagreement the situation is dialectically symmetric in that both sides are rational, have reasons for their views, understand each other's reasons but still cannot rationally convince each other. I am not ruling out cases in which my opponent is a nonhuman animal, because it does not really matter whether the dispute is an actual one or not. It is enough that I can imagine someone - be it an animal or a human being - whose appearances differ from mine but could in principle be defended just as well as mine. It is not necessary for my opponent to be an actual one: I can go through the dialectic solely in my head.

The second point is that we must distinguish two different cases of such irresolvable disagreements. In one case I am not a participant in the disagreement. I have no beliefs about the matter under dispute, neither do I have reasons for preferring either side. I am in the position of an impartial judge. If the disagreement is serious in the way described it is clear that I should suspend belief. Choosing one of the disputing parties and declaring it the winner would be completely arbitrary.

In the other case I am a participant in the dispute. I have my own beliefs about the matter, there are others who disagree with me and we cannot rationally resolve our disagreement. Assume that the situation is otherwise the same as in the first case, the only difference being that I am now a participant. The question is why should these cases be normatively different? If I should suspend belief in one case, I should do so in the other. I should give up my belief and not prefer one side of the dispute simply 
because it is mine. I should look at it from an impartial point of view and suspend belief. This is exactly what Sextus demanded in the two quotations above.

Now we can also understand why serious irresolvable disagreements must be dialectically symmetric. Serious disagreements are such that an impartial judge is not able to decide them. The skeptic asks me to imagine a disagreement of a certain kind and to adopt an impartial point of view. If the disagreement is dialectically symmetric I cannot decide from that point of view who is right and who is wrong, so I should suspend belief about it. It does not matter whether or not I was originally a participant in the dispute. As soon as I take a detached position I see that my reasons are not good enough, and realize that I should suspend belief.

The third and final point is that this "should" must be understood epistemically. The skeptic argues that it is not epistemically rational or justified for me to retain my belief. If I am an inquirer interested in truth I should suspend it. This is not to deny that it might be practically rational for me to retain it. It may be psychologically impossible for me to give it up, but as a truth-seeker, I should do so.

These three points make the premises of the Pyrrhonian argument at least initially quite plausible. Take any of my beliefs about the nature of reality. The skeptic points out that there is a serious irresolvable disagreement about the matter. I believe that $p$, but there are others who believe that $\sim \mathrm{p}$. I cannot convince them in any rational way, neither can they convince me. Our disagreement is rationally irresolvable. It seems that it would be quite arbitrary for me to prefer my own belief in such a situation. Assuming that I am a sincere inquirer who is solely interested in truth, I should give up my belief. This all seems quite plausible. However, because the skeptic can use the same argument against any of my beliefs about reality this conclusion is quite unacceptable. It means that I should give up all inquiry.

How, then, should I respond to the argument? If I want to avoid skepticism there are two options: to deny either the first or the second premise. I must explain to myself why, contrary to initial appearances, one of the premises is false. I must explain how I can be justified in believing that $\mathrm{p}$, in spite of being aware of apparently irresolvable disagreements about it. There are two basic approaches. First, I could grant that 
justification does require that I be able to resolve all or at least all serious disagreements about $\mathrm{p}$, and then explain how I can rationally resolve them. I could thus deny the first premise, that there are serious rationally irresolvable disagreements about $p$. Second, I could deny that justification requires dialectically effective reasons and explain how I can be justified in believing that $\mathrm{p}$, in spite of being aware of the existence of irresolvable disagreements about p. In this case I would deny the second premise.

Thus there are two possible epistemological approaches to the Pyrrhonian problem. On the one hand justification and knowledge are taken to be dialectical notions requiring me to defend my belief in a dialectically effective way and thus to resolve disagreements about the truth of it. I take this to be the traditional approach in epistemology that derives from Plato and Aristotle. It is evident in Descartes, and also in otherwise very different philosophers such as Peirce, Hegel, Wittgenstein, Sellars, Rorty, Brandom and Williams. On the other hand, things are very different from the perspective of contemporary analytical epistemology, the received view being that justification and knowledge are independent of dialectic. It is one thing to be justified in one's beliefs and to know, but it is quite another to be able to defend oneself in the public arena. Justification and knowledge are non-dialectical notions. ${ }^{6}$

What I aim to do now is to show that neither of these approaches offers an intuitively plausible resolution of the Pyrrhonian problem. If this is the case, the argument from disagreement constitutes a genuine skeptical paradox, there being no completely satisfactory resolution of it.

The dialectical conception seemed to be widely accepted in Ancient and early Modern philosophy. Descartes, for example, apparently did so, according to the following passage from Rules for the Direction of the Mind:

Whenever two persons make opposite judgments about the same thing, it is certain that at least one of them is mistaken, and neither, it seems, has knowledge. For if the reasoning of one of them were certain and evident, he would be able to lay it before the other in such a way as eventually to convince his intellect as well. (CSM I, p. 11) 
Descartes thus seemed to accept the dialectical conception of justification and thereby the second premise of the Pyrrhonian argument. In order to reject the first premise he therefore had to show how disagreements could be resolved, which was the task he set himself in Meditations.

Descartes began by trying to find propositions that could not be rationally doubted, and then used them in order to show that God existed and that clear and distinct perceptions were true. This was done in steps that were also rationally indubitable, so that any rational being following these meditations would become convinced of the conclusion. $^{7}$

If Descartes were successful in his project he would be able to show how all possible disagreements between rational beings could be resolved, and perhaps these are the only disagreements we need to care about. It would be hopeless to try to rationally convince someone who is not rational. Unfortunately, it seems there are not enough rationally indubitable propositions and inferential steps for accomplishing the task. Thus the Cartesian project seems to land in skepticism.

Charles Peirce claimed that Descartes' hypothetical doubts were artificial, and suggested that we should start inquiry (and argument) from propositions that were not actually doubted. ${ }^{8}$ However, it seems that we still lack a sufficient number of uncontested propositions that would lead all inquirers to an agreed view of reality. Furthermore, is it well motivated to restrict the scope of serious disagreements to the actual ones? This would mean that we could gain knowledge by killing our opponents. Then there would no longer be actual disagreements.

One could still enlarge the starting point to propositions that are not and perhaps cannot be doubted in a particular context of inquiry. They are and can be doubted in other contexts, but this does not affect inquiry that is directed by the context in question. According to this sort of contextualist view we can resolve local disagreements that arise within a particular context. Justification is thus always relative to a context. In every context there are some propositions that cannot be legitimately doubted or challenged, and that can therefore be used for resolving 
disagreements about other matters. ${ }^{9}$ However, this leaves us with irresolvable disagreements between different contexts. Why are these supposed to be less serious? Of course, one could convert to some form of relativism that denies the possibility of disagreement across contexts, but we assumed that relativism is problematic.

If the dialectical conception of justification leads to insurmountable problems, why cannot we reject it and with it the second premise of the Pyrrhonian argument? The two most popular contemporary theories of justification that are non-dialectical are reliabilism and evidentialism, both of which make justification a function of factors that have nothing to do with dialectic. Reliabilism takes it to be a function of the reliable causal origin of belief, whereas according to evidentialism, a belief justified to the extent that evidence - composed of the subject's mental states - supports it. Both allow knowledge and justified belief even if one cannot defend oneself without begging the question. Knowledge and justified belief do not require dialectically effective reasons. What is wrong with this view?

Reliabilism entails that, in an irresolvable disagreement, one party may still be justified in his or her belief. Which one? It is the one whose belief is, in fact, based on reliable sources. If the sources of my belief are reliable then I am justified in retaining it; and if there are no such sources for your belief, then you should give it up. ${ }^{10}$ This seems absurd. Neither of us is necessarily aware of these sources. Perhaps, we have no beliefs about their nature and reliability. Thus we are both in the dark about the reliability of our sources. In such a case it seems intuitively right that both of us should suspend belief about the matter under dispute and continue inquiry - in spite of the fact that one of us really has reliable sources. Thus, simple reliabilism does not seem to resolve the problem.

What happens in the case of evidentialism? I assume here an internalist form of evidentialism because with externalist forms the situation would be same as with reliabilism. Thus, if we assume that evidence is understood internally, as being composed of non-factive mental states, it seems that both parties in an irresolvable disagreement may have evidence that supports their beliefs and thus be justified in retaining them. Does this internalist view explain why the second premise is false, and why I can justifiably retain my belief about the matter under dispute? It seems that if I 
am really interested in truth I cannot be happy with this explanation, according to which we are both justified in our disagreeing beliefs. This sort of justification does not decide who is right, and I should therefore not, as an inquirer, be happy with it. I should rather suspend belief and continue inquiry.

An example serves to show the problems of these non-dialectical views more clearly. It may be somewhat artificial but it closely resembles the situation that Sextus describes in the first of the ten modes, ${ }^{11}$ and illustrates more generally the structure of serious irresolvable disagreements. Assume that I have a thermometer that I trust and that you have another thermometer that you consider trustworthy, and we stick our thermometers into the same bucket of water. Mine shows that the temperature is $18^{\circ} \mathrm{C}$ and yours shows that it is $20^{\circ} \mathrm{C}$. Let us suppose that we both initially trust our own thermometers, and that I believe that the temperature is $18^{\circ}$ and you believe that it is $20^{\circ}$. So we disagree. Let us assume that we have no other evidence than our thermometers about the temperature, and that we cannot thus rationally resolve our disagreement.

I think we have the intuition that in such a situation we should both give up our beliefs about the temperature. Yet, it seems to follow from reliabilism and evidentialism that one or even both of us may be justified in retaining our beliefs. If my thermometer is, in fact, reliable then according to reliabilism my belief about the temperature is justified, and if your thermometer is, in fact, unreliable then your belief is not justified and you should give it up; or it may be the other way around.

On the other hand, if justification depends on evidence rather than reliability, as internalist evidentialism posits, we may both be justified. The evidence provided by my thermometer supports my belief, and the evidence of your thermometer supports yours. We are both justified in retaining our beliefs. Both views are extremely counterintuitive. They allow justified beliefs too easily.

These non-dialectical accounts of justification may avoid skepticism, but the problem is that they do so by allowing justified beliefs and knowledge in a way that is intuitively too easy. They allow me justified beliefs and knowledge about the temperature in spite of my being aware that your thermometer gives you contrary 
evidence. Things might be different if I were justified in believing that my thermometer was reliable, or that my evidence was indicative of the truth. It seems that I cannot rationally prefer my belief to yours unless I am justified in believing that my sources rather than yours are reliable, or that my evidence rather than yours is indicative of the truth. This is quite compatible with reliabilism and evidentialism in that they allow that my awareness of the disagreement defeats my justification. If this is the case I can defeat this defeater and regain the justification only if I am justified in believing that my source or my evidence is reliable, rather than yours.

How, then, can I attain justification for my belief that my sources rather than yours are reliable? Suppose I reason in the following way:

(1) My thermometer reads that the temperature is $18^{\circ} \mathrm{C}$.

(2) The temperature is $18^{\circ} \mathrm{C}$.

(3) So my thermometer is reading accurately on this occasion.

According to reliabilism I can very well thereby gain a justified belief. My belief in (1) is based on my reliable vision. Because my thermometer is in fact reliable, my belief that the temperature is $18^{\circ} \mathrm{C}$ is also justified. Further, because deduction is a reliable process I gain a justified belief by concluding that my thermometer is reading accurately - that it gives the right temperature. I can even conclude by deduction that your thermometer is not reading accurately and that there must be something wrong with it.

If simple evidentialism is true, I can attain a justified belief in the same way. The only difference is that evidentialism, unlike reliabilism, allows that you can also attain a justified belief that your thermometer is reading accurately. Once again, both allow justified beliefs in a way that is intuitively too easy. It seems clear that I cannot attain a justified belief that my thermometer is accurate simply by looking at it, and I cannot form on this basis a further justified belief that yours is not. Neither can I know that mine is accurate even if, in fact, it is.

Reliabilism and evidentialism also allow that I can easily attain a justified belief about the global or general reliability of my thermometer. Suppose that I have earlier 
gathered evidence of its reliability and that I now remember this evidence. Let us assume that this evidence is also based on my trusting my thermometer. I infer in the following way:

At $t_{1}$, my thermometer reads that the temperature is $15^{\circ}$, and the temperature is $15^{\circ}$.

At $t_{2}$, my thermometer reads that the temperature is $13^{\circ}$, and the temperature is $13^{\circ}$.

At $t_{n}$, my thermometer reads that the temperature is $19^{\circ}$, and the temperature is $19^{\circ}$.

So my thermometer is reliable.

Assuming that my memory, vision and inductive reasoning are reliable processes and that my thermometer is, in fact, reliable, it follows from reliabilism that I can thereby gain a justified belief. Further, if evidentialism is true we can both gain justified beliefs in the reliability of our thermometers. Here I am using my thermometer to obtain evidence of its reliability. William Alston (1986) calls arguments of this sort epistemically circular. The intuition is that such arguments allow justified beliefs and knowledge about reliability too easily.

Stewart Cohen (2002, 309-11) argued recently that we can avoid easy knowledge based on epistemic circularity by accepting the following principle, which he calls the KR principle:

(KR) A potential knowledge source K can yield knowledge for S, only if S knows that $\mathrm{K}$ is reliable.

The principle concerns the general or global reliability of a source. If we understand the reliability in question in the local sense it may also be possible to avoid easy knowledge in the case concerning the accuracy of the thermometer on a particular occasion. Furthermore, an analogous principle concerning justification might avoid cases of easy justified belief. However, this is not quite right. 
Let us focus on the KR principle in the sense of global reliability. It denies that I can know the premises of the epistemically circular track-record argument for the reliability of my thermometer prior to knowing the conclusion. Thus it may seem that I cannot come to know the conclusion by reasoning from the premises. In order to know the premises I must already know the conclusion. However, this is not quite right because the principle allows that I come to know the premises and the conclusion simultaneously.

According to holistic coherentism, knowledge is generated simultaneously in the whole system of beliefs once a sufficient degree of coherence has been achieved. As James Van Cleve $(2003,55-57)$ points out, this does not avoid the problem of easy knowledge, but rather allows that we gain knowledge through epistemically circular reasoning. The steps by which we gain such knowledge may be exactly the same as in the foundationalist version. The only difference is that when, according to foundationalism, knowledge is first generated in the premises and then transmitted to the conclusion, coherentism makes it appear simultaneously in both. It thus accepts the KR principle but still makes knowledge about reliability too easy.

In the thermometer case it is assumed that I have trusted my thermometer in the past. I therefore believe the premises of the track-record argument. If I now deny the conclusion or even suspend belief about its truth, my system of beliefs is not coherent, but if I also come to believe the conclusion it becomes coherent. According to coherentism, this coherence provides justification both for my beliefs in the premises and my belief in the conclusion simultaneously. Yet this is still too easy a way to attain knowledge about the reliability of the thermometer.

Ernest Sosa (1997) suggests that we can resolve the Pyrrhonian problem if we use his distinction between animal knowledge and reflective knowledge, but as both Cohen $(2002,326)$ and Van Cleve $(2003,55-57)$ point out, this account also too easily allows knowledge about reliability. Animal knowledge is knowledge as it is understood in simple reliabilism: it merely requires a true and reliably formed belief. It therefore does not satisfy the KR principle and thus allows easy knowledge. We can attain animal knowledge about the reliability of the thermometer through epistemically circular reasoning. 
Sosa's point is that reflective knowledge satisfies the principle. It requires, in addition to animal knowledge, a coherent system of beliefs that includes an epistemic perspective on the reliability of the sources of belief. Thus a source gives me reflective knowledge only if I know that it is reliable. However, it is still true that the epistemically circular track-record argument provides me with all the necessary ingredients for such reflective knowledge: I attain animal knowledge about reliability through reasoning from my animal knowledge about the truth of the premises. Once I have attained this knowledge, my system of beliefs also achieves a sufficient degree of coherence to transfer my animal knowledge into reflective knowledge. All this still happens too easily, however. In fact, it happens as easily as before. The only difference is in the points at which different sorts of knowledge are attained. The reasoning is exactly the same.

It seems that we can avoid allowing easy knowledge only by strengthening the KR principle. It must require that knowledge of the reliability of source $K$ be prior to knowledge based on $K$. We must know that the source is reliable independently of any knowledge based on it. The problem with coherentism and Sosa's account seems to be that they reject this strengthened KR principle, and this is why they make knowledge too easy.

However, by affirming the strengthened KR principle we avoid the problem of easy knowledge but we are in danger of falling into skepticism. This strengthened principle leads to the following of criterion problem:

(1) We can know that a belief based on source $K$ is true only if we first know that $K$ is reliable.

(2) We can know that $K$ is reliable only if we first know that some beliefs based on source $K$ are true.

Assumption (1) is a formulation of the strengthened KR principle. Together with assumption (2) it leads to skepticism: we cannot know which sources are reliable nor which beliefs are true. To be sure, (2) does not require us to know that beliefs based on $K$ are true through $K$; we can rely on some other source. However, (1) posits that 
this other source can deliver knowledge only if we first know that it is reliable, and (2) that, in order to know this, we need to know that some beliefs based on it are true. In order to know this, in turn, we may once again have to rely on some third source, and so on. However, because we cannot have an infinite number of sources, sooner or later we have to rely on sources already relied on at some earlier point. We are thus reasoning in a circle, and circular reasoning is unable to provide knowledge.

The circle we are caught in is not epistemic. It is a straightforwardly logical circle. It is clear that a logical circle does not produce knowledge. Such a circle is nowhere connected to reality. Thus in trying to avoid epistemic circularity and easy knowledge we become caught in a more clearly vicious circle - a logical circle.

Can we avoid this circle? I have shown that denying the first premise leads to easy knowledge. We could deny the second premise if we had basic or non-inferential knowledge about the reliability of our sources, but how is that possible? That a source of belief is reliable is a contingent generalization. We cannot have basic a priori knowledge about it, but what other basic knowledge about it could there be ${ }^{12}$ It thus seems that if we are to have any knowledge about reliability it must be based on reasoning. However, then the second premise is true and we are in the circle.

In sum, it seems that all our attempts to respond to the Pyrrhonian argument lead to a dilemma: the suggested accounts of knowledge or justification either make knowledge or justified belief intuitively too easy or they make them impossible. Because the resulting accounts are all counterintuitive, it does not matter whether we understand epistemic terms dialectically or non-dialectically. None of them offers what a sincere truth-seeker needs: an impartial way of deciding between competing views. This shows that the argument from disagreement forms a genuine skeptical paradox. ${ }^{13}$

\section{References}

Alston, William P. "Epistemic Circularity.” Philosophy and Phenomenological Research 47 (1986). Reprinted in Epistemic Justification: Essays in the 
Theory of Knowledge. Ithaca: Cornell University Press, 1989: 319-349.

Annas, Julia, \& Barnes, Jonathan. 1985. The Modes of Scepticism. Cambridge:

Cambridge University Press.

Annis, David. 1978. "A Contextualist Theory of Justification.” American

Philosophical Quarterly 15, 213-219.

Audi, Robert. 1993. "The Foundationalism-Coherentism Controversy." In The

Structure of Justification. Cambridge: Cambridge University Press.

Brandom, Robert. 1994. Making It Explicit. Cambridge: Harvard University Press.

Christensen, David. 2007. "Epistemology of Disagreement: the Good News." The

Philosophical Review 116, 187-217.

Cohen, Stewart. 2002. "Basic Knowledge and the Problem of the Problem of Easy

Knowledge." Philosophy and Phenomenological Research 65: 309-329.

Elga, Adam. 2007. "Reflection and Disagreement." Noûs 41, 478-502.s[ep?

Feldman, Richard. 2006. "Epistemological Puzzles about Disagreement.” In Stephen Hetherington (ed.), Epistemology Futures. Oxford: Oxford University Press.

Gutting, Gary. 1982. Religious Belief and Religious Skepticism. Notre Dame:

University of Notre Dame Press.

Kelly, Thomas. 2005. "The Epistemic Significance of Disagreement.” In Tamar Szabó

Gendler and John Hawthorne (eds.), Oxford Studies in Epistemology, Vol. 1.

Oxford: Clarendon Press, 167-196.

Lammenranta, Markus. 2008. "The Pyrrhonian Problematic.” In J. Greco (ed.), The

Oxford Handbook of Skepticism. Oxford: Oxford University Press, 9-33.

Lammenranta, Markus. 2009. "Epistemic Circularity." The Internet Encyclopedia of

Philosophy, <http://www.iep.utm.edu/e/ep-circ.htm>, 6/1/09.

Peirce, Charles S. 1958. "Some Consequences of Four Incapacities.” In Selected

Writings. Ed. by Philip P. Wiener. New York: Dover.

Sextus Empiricus. 2000. Outlines of Skepticism. Ed. by Julian Annas \& Jonathan

Barnes. Cambridge: Cambridge University Press.

Sosa, Ernest. 1997. "How to Resolve the Pyrrhonian Problematic: A Lesson from

Descartes.” Philosophical Studies 85, 227-249.

Williams, Michael. 1988. "Skepticism without Theory." Review of Metaphysics 41.

Williams, Michael. 2001. Problems of Knowledge. Oxford: Oxford University Press.

Wittgenstein, Ludwig. 1969. On Certainty. Oxford: Blackwell. 
${ }^{1}$ It is thought that only disagreement between people who take themselves to be epistemic peers may have skeptical consequences. Epistemic peers are supposed to share the relevant evidence and to be equally competent in evaluating it. It is clear that such disagreements are not very common. See Gutting 1982, 83; Kelly 2005, Feldman 2006; Christensen 2007; Elga 2007.

${ }^{2}$ In my reconstruction of skeptical reasoning I understand the conclusion normatively. Many scholars read Sextus rather as talking about some sort of causal or psychological necessity: my awareness of disagreements forces me causally to suspend belief (see for example Annas \& Barnes 1985, 25). There is textual evidence for both readings. My reason for preferring the normative interpretation in my rational reconstruction is that the causal interpretation does not provide a serious skeptical problem. See Lammenranta 2008 and the comments on Williams below.

${ }^{3}$ I formulate the argument in the first person, because it is not necessary that there is an actual skeptic. I can simply imagine such a skeptic, or just pose the argument to myself. What is essential is that the argument has plausible premises and an implausible conclusion, that it forms a paradox.

${ }^{4}$ Of course, there is disagreement in the sense that one party affirms and the other denies one and the same proposition. Yet, according to relativism, this is not a genuine disagreement in the sense that they can both be right.

${ }^{5}$ However, see Lammenranta 2008, 26-29.

${ }^{6}$ Robert Audi $(1993,145)$ expresses this common view in this way: "It would seem that just as a little child can be of good character even if unable to defend its character against attack, one can have a justified belief even if, in response to someone who doubts this, one could not show that one does."

${ }^{7}$ Because the first premises concern Descartes' own thoughts, it is assumed that everybody goes through the meditations in his or her own thoughts.

${ }^{8}$ See especially Peirce $(1958,40)$.

${ }^{9}$ For this sort of dialectical contextualism inspired by Wittgenstein (1969), see Annis (1978), Brandom (1994, 176-178) and Williams (2001).

${ }^{10}$ Because reliability does not entail truth, it is possible - though improbable - that we have both reliable sources, in which case we are both justified in our beliefs.

${ }^{11}$ Sextus (PH 1.40-78) argues that, because of the differences in the sense organs of animals of different species, things appear differently to their senses. Non-human animals cannot naturally argue with us, but we can very well imagine how they would defend the reliability of their sensory faculties if they could. This sort of possible disagreement may be enough for the skeptic's purposes.

${ }^{12}$ Even if our theory allowed basic reliability knowledge, such knowledge would still be intuitively too easy. See Lammenranta 2009. 
${ }^{13}$ I thank Raul Hakli and the participants of the congress, especially Ernest Sosa, Richard Bett, Roberto Polito, Michael Williams, Svavar Svavarsson, Juan Comesaña and Diego Machuca, for their useful comments. 